\title{
Monolayers and Thin Films of Dextran Hydrophobically Modified
}

\author{
Angel Leiva, ${ }^{*, a}$ Natalia Muñoz, ${ }^{a}$ Marcela Urzúa,${ }^{b}$ Ligia Gargallo ${ }^{a}$ and Deodato Radic ${ }^{a}$ \\ ${ }^{a}$ Departamento de Química Física, Facultad de Química, Pontificia Universidad Católica de Chile, \\ Casilla 302, Correo 22, Santiago, Chile \\ ${ }^{b}$ Departamento de Química, Facultad de Ciencias, Universidad de Chile, \\ Casilla 653, Correo Central, Santiago, Chile
}

\begin{abstract}
Foram sintetizados uma série de copolímeros enxertados biodegradáveis pelo enxerto da $\varepsilon$-captolactona sobre dextrana de diferentes pesos moleculares. Os polímeros obtidos foram caracterizados por infravermelho com transformada de Fourier, ressonãncia magnética nuclear, termogravimetria e análise elementar. Monocamadas estáveis na interface ar-água e filmes finos de revestimento por rotação foram preparados e caracterizados pela técnica de Langmuir e por medidas de angulo de contato. A compressibilidade e elasticidade estática superficial das monocamadas e a energia de superfície dos copolimeros de filme finos mostram dependência com a quantidade de $\varepsilon$-caprolactona. Desses resultados pode-se concluir que as propriedades de superfície de polímeros enxertados podem ser moduladas pela sua composição. Adicionalmente, de acordo com esses resultados, dextranas enxertadas com $\varepsilon$-caprolactona mostram potencial para serem usadas em diferentes aplicações onde as propriedades de superfície são importantes.
\end{abstract}

A series of biodegradable graft copolymers were synthesized by grafting $\varepsilon$-caprolactone over dextran of different molecular weights. The obtained copolymers were characterized by Fourier transform infrared spectroscopy FTIR, proton nuclear magnetic resonance ${ }^{1} \mathrm{H}$ NMR, thermogravimetry and elemental analysis. Stable monolayers at the air-water interface and spin coated thin films were prepared and characterized by the Langmuir technique and by contact angle measurements respectively. The compressibility and static surface elasticity of the monolayers and the surface energy of copolymer thin films show dependence with the $\varepsilon$-caprolactone content. From these results it can be concluded that the surface properties of grafted copolymers can be modulated by their composition. Additionally, according to the obtained results, $\varepsilon$-caprolactone grafted-dextrans show potential for being used in different applications where surface properties are important.

Keywords: dextran, $\varepsilon$-caprolactone, block copolymers, biodegradable, copolymers

\section{Introduction}

In the last decades we have witnessed a remarkable concern for environmental protection and for the control of environmental contamination. For this reason, a great quantity of research has been developed focusing on the study of nontoxic and biodegradable materials. In the polymer field, biodegradable polymers have been studied extensively, focusing on their contribution towards diminishing the environmental problems caused by non biodegradable materials, as well as, on specific

*e-mail: aleivac@uc.cl applications in fields like pharmaceutical formulations, where biodegradation is also important.

The origin of biodegradable polymers can be natural or also via synthesis. The technological evolution of natural biodegradable polymers has been developed mainly through chemical modification of their chains or by modulating the biosynthetic process. In the case of synthetic polymers this has been done by means of chemical modulation of their composition during the polymerization process, or by chemical modification of presynthesized polymers. ${ }^{1}$ However, some properties of biodegradable polymers restrict their potential applications. For these reasons, the mixture process and copolymerization of these materials have been 
used to reinforce properties such as biodegradation rates, permeability and mechanical properties., ${ }^{2,3}$

In the biodegradable polymer field, polyesters and natural polymers are highlighted due to the great interest that their properties cause in scientific and technological research.

Biodegradable polyesters and their copolymers have been extensively studied in recent years due to the wide range of possible applications in different fields such as biomedicine, drug delivery and tissue engineering. ${ }^{4}$

In biomedical applications, polysaccharide-based polymers are interesting and potentially useful materials since they may have per se chemical groups that can participate in recognition, allowing specific adhesion or receptor recognition. ${ }^{5}$

Dextran possesses excellent biocompatibility and has been widely used in biomedicine, for example as a carrier for a variety of agents such as proteins, enzymes, peptides and drugs. ${ }^{6}$

Poly( $\varepsilon$-caprolactone) grafted dextran copolymers have been studied widely. Among the most frequent reports are those that focus on the amphiphilic properties of the copolymers because of their potential applications in the pharmaceutical and biomedical fields. Poly( $\varepsilon$-caprolactone) grafted dextran films loaded with Paclitaxel, a natural alkaloid used in treatment of ovarian and breast cancer, were prepared and their in vitro release rates were determined. ${ }^{6}$ The physicochemical characterization of self-assembled $\varepsilon$-caprolactone grafted-dextran to form a core-shell type nanoparticle, in solution, has been studied. ${ }^{4}$ Gref et al. ${ }^{5}$ also report the synthesis and characterization of nanoparticles of this material for controlled release of bioactive compounds.

Other interesting characteristics of dextran copolymers are the emulsifying properties of Polylactide-grafted dextrans and the interfacial behavior of polystyrenepolysaccharide diblock copolymers and the surface activity of hydrophobically modified dextrans..$^{7-10}$

In this work we study the behavior shown by graft copolymers of $\varepsilon$-caprolactone on polysaccharide dextran of different molecular weights, when they are spread at the air-water interface. According to our knowledge, there is no report about the behavior of these polyester graftedpolysaccharide at the air-water interface. This aspect is very important because the adsorption and spreading processes of macromolecules at interfaces are of great interest for various industrial and technological applications.

\section{Experimental}

\section{Materials}

Dextrans $\left(10,000\right.$ and 40,000 $\left.\mathrm{g} \mathrm{mol}^{-1}\right), 1,1,1,3,3,3$-hexa- methyldisilazane (HMDS), $\varepsilon$-caprolactone and stannous 2-ethylhexanoate $\left(\mathrm{Sn}(\mathrm{Oct})_{2}\right)$ were purchased from Aldrich Chem. Co.

Solvents were purchased from Merck, and were purified by standard procedures (drying, distillation and storage in nitrogen atmosphere). Dextrans were dried under reduced pressure at $90{ }^{\circ} \mathrm{C}$ for $12 \mathrm{~h}$. $\varepsilon$-caprolactone was dried over $\mathrm{CaH}_{2}$ for $48 \mathrm{~h}$ and distilled under reduced pressure. The rest of the reagents were used without any further purification.

\section{Dextrans modification}

Poly( $\varepsilon$-caprolactone)-grafted dextrans were synthesized in two consecutive steps according to reported methods, ${ }^{11,12}$ with the minor modifications that are indicated in the following procedure.

\section{Dextrans protection}

Over a solution of dextran $(1 \mathrm{~g})$ in DMSO $(30 \mathrm{~mL})$, $7.8 \mathrm{~mL}$ of HMDS were added under reflux and nitrogen flow. The reaction mixture was stirred for $16 \mathrm{~h}$ at $50{ }^{\circ} \mathrm{C}$. $10 \mathrm{~mL}$ of tetrahydrofurane (THF) were added when the reaction mixture became cloudy. The product was precipitated with heptane, filtered and dried under reduced pressure until constant weight.

\section{Grafting of $\varepsilon$-caprolactone}

The product obtained in the previous step was dissolved in toluene and dried by azeotropic distillations of toluene. Over $10 \% \mathrm{~m} / \mathrm{m}$ of silylated dextran in dried toluene solution under reflux at $100{ }^{\circ} \mathrm{C}$, $\varepsilon$-caprolactone and $\mathrm{Sn}(\mathrm{Oct})_{2}$ as catalyst were added to obtain $[\varepsilon-\mathrm{CL}] /[\mathrm{OH}]$ free and $[\mathrm{Cat}] /[\mathrm{OH}]$ free ratios of 10 and 0.05 respectively. The reaction mixtures were vigorously stirred for 44 and $70 \mathrm{~h}$. The products were precipitated with heptane and dried under reduced pressure until constant mass. Four samples were obtained, two from dextran $10,000 \mathrm{~g} \mathrm{~mol}^{-1}$ with 44 and $70 \mathrm{~h}$ of reaction with $\varepsilon$-CL, and two from dextran 40,000 at the same reaction times. Copolymers were labeled as g-dextran 1 and g-dextran2 for those obtained from dextran 10,000 $\mathrm{g} \mathrm{mol}^{-1}$ at 44 and $70 \mathrm{~h}$ of copolymerization, and g-dextran 3 and g-dextran4, for those obtained from dextran 40,000 $\mathrm{g} \mathrm{mol}^{-1}$ at 44 and $70 \mathrm{~h}$ of copolymerization respectively.

The synthesis procedure is summarized in Scheme 1.

\section{Molecular characterization}

The products were characterized by Fourier transform infrared spectroscopy (FTIR) and ${ }^{1} \mathrm{H}$ NMR. 

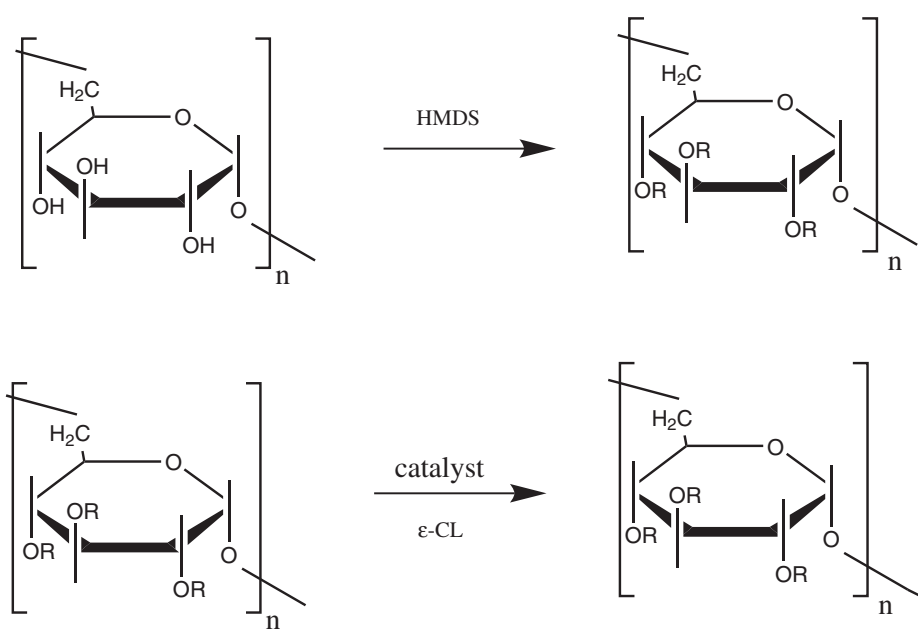

$\mathrm{R}=\mathrm{Si}\left(\mathrm{CH}_{3}\right)_{3}$ or $\mathrm{H}$

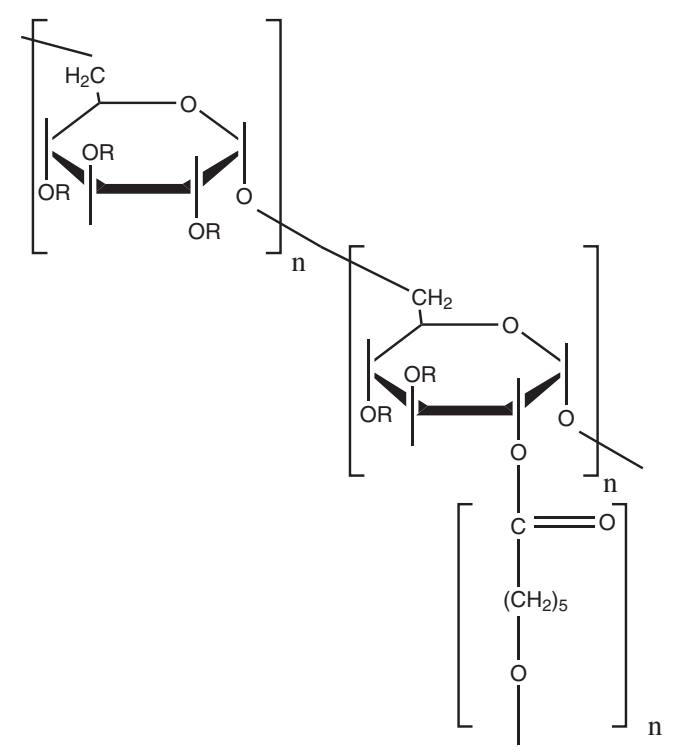

Scheme 1

\section{Elemental analysis}

To carry out the determination of the carbon and hydrogen contents in the obtained samples, an analyzer of elements EA 1108, CE Instruments, configured to simultaneous determination of the carbon, hydrogen, nitrogen and sulfur contents, was used.

\section{Thermogravimetric analysis}

Dynamic thermogravimetric measurements were performed using a Mettler calorimetric system TGA/ SDTA 851e. The thermogravimetric results were processed using the STAR program. The samples were heated on $\mathrm{Al}_{2} \mathrm{O}_{3}$ pans. Measurements were carried out between 298 and $973 \mathrm{~K}$ at $20 \mathrm{~K} \mathrm{~min}^{-1}$ under nitrogen atmosphere at $60 \mathrm{~mL} \mathrm{~min}^{-1}$ flow.

\section{Surface energy}

Surface energies for polymer films spin-casted onto glass slides were determined by static contact angle measurements of $\mathrm{H}_{2} \mathrm{O}$ and diiodomethane $\left(\mathrm{MeI}_{2}\right)$ using the sessile drop, and the Owens, Wendt and Kaelble method. ${ }^{13,14} \mathrm{~A}$ Dataphysics OCA 20 device with a conventional goniometer and high performance video camera, controlled by SCA20 software, was used to measure the optical contact angle.

\section{Monolayers at the air-water interface and surface pressure/ area isotherms}

Monolayers were obtained by the spreading of copolymer samples on aqueous subphase from chloroform. The concentrations of the spread solutions for different samples were $0.20 \mathrm{mg} \mathrm{mL}^{-1}$ and the temperature was 298.1 K. The water subphase was purified by a Millipore Milli-Q system (resistivity greater than $18.0 \mathrm{M} \Omega \mathrm{cm}$ ).

Polymer monolayers on the aqueous subphase were studied by the Langmuir technique. Surface pressure/ area $(\pi / \mathrm{A})$ isotherms, were obtained using a Nima Model 611 surface film balance (NIMA Instruments, Coventry, UK). The entire system was covered with a box of poly (methyl methacrylate) in order to prevent environmental perturbations. A constant compression rate of $10 \mathrm{~cm}^{2} \mathrm{~min}^{-1}$ $\left(16.7 \mathrm{~mm}^{2} \mathrm{seg}^{-1}\right)$ was used in all experiments. The experiments were carried out in triplicate to ensure their reproducibility. 


\section{Results and Discussion}

\section{Spectroscopic characterization}

The main signals in the ${ }^{1} \mathrm{H}$ MNR spectra of products correspond to the expected structure, i.e., the main signals of the protected dextran are: $-\mathrm{CH}_{3}$ protons of protective groups at $0.15 \mathrm{ppm}$, glucosidic protons 3.2-4.2 ppm, anomeric protons 4.6-5.0 ppm. For Dextrans grafted with PCL signals of $-\mathrm{CH}_{3}$ protons of protective groups at $0.15 \mathrm{ppm}$, glucosidic protons $3.2-4.2 \mathrm{ppm}$, anomeric protons 4.6-5.0 ppm were also obtained, furthermore $-\mathrm{CH}_{2}-\mathrm{O}-$ and $-\mathrm{CH}_{2}-\mathrm{CO}-\mathrm{O}-$ protons from PCL appear at 4.1 and $3.0 \mathrm{ppm}$ respectively.

The FTIR spectrum also agrees with the expected copolymer structure and shows characteristic signals of $\varepsilon$-caprolactone carbonyl units at $1,725 \mathrm{~cm}^{-1}, \mathrm{OSi}\left(\mathrm{CH}_{3}\right)_{3}$ at $750,842,874,1,020,1,156$ and $1,250 \mathrm{~cm}^{-1}$, and $-\mathrm{OH}$ from dextran and $\varepsilon$-caprolactone ends at $3,500 \mathrm{~cm}^{-1}$.

Figure 1 shows as an example the FTIR and ${ }^{1} \mathrm{H}$ MNR spectra for g-dextran1. For the other modified dextran samples, the spectra are similar.
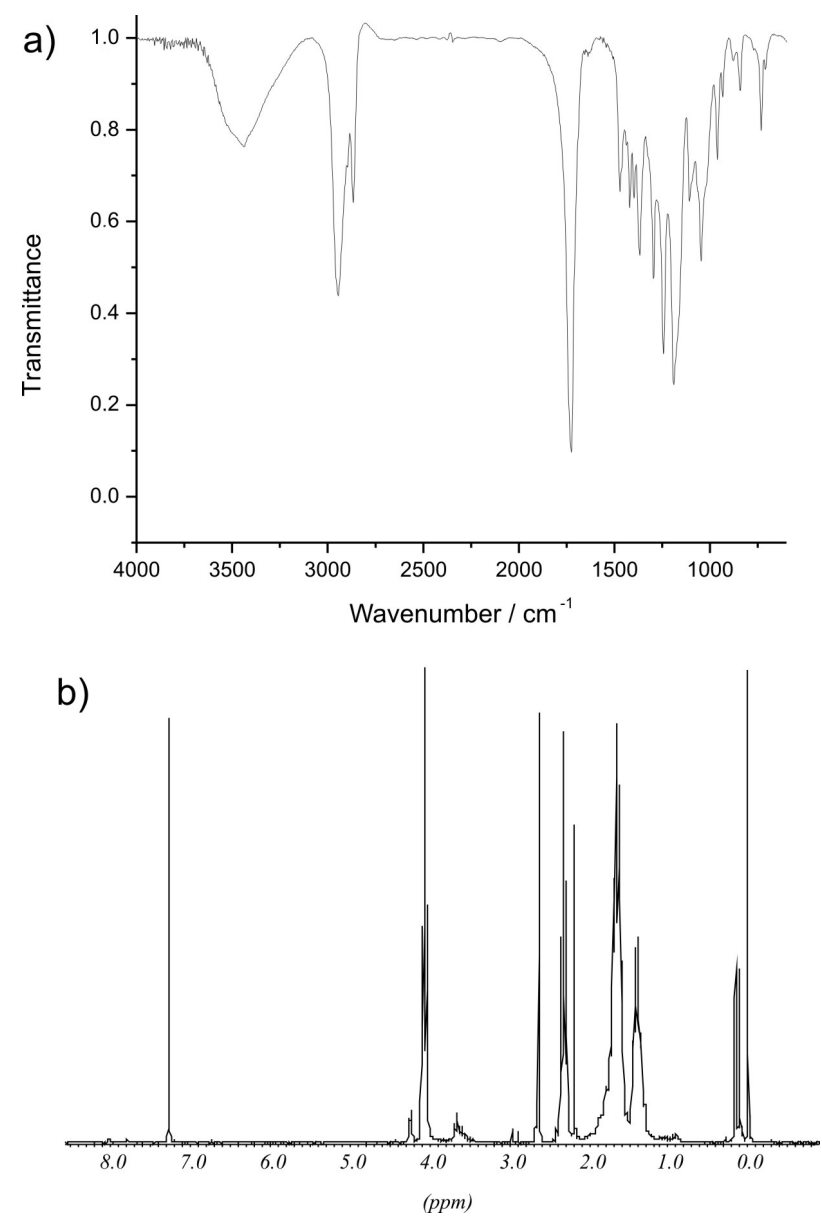

Figure 1. FTIR (a) and ${ }^{1} \mathrm{H}$ MNR (b) spectra for g-dextran1.
From the respective ${ }^{1} \mathrm{H}$ MNR spectra, the protection percent of hydroxyl groups and the amount of PCL incorporation were calculated as indicated below. $7,11,12,15$

The protection amount was calculated according the following equation:

Protection $\%=\frac{A_{\mathrm{OSiMe}_{3}} \times 6 \times 100}{A_{\text {glu cosidic }} \times 27}$

where; $\mathrm{A}_{\mathrm{OSiMe} 3}$ is the integrated signal of $\mathrm{A}_{\mathrm{OSi}(\mathrm{CH} 3) 3}$ groups at $0.15 \mathrm{ppm}$ (27 protons for each completely protected unit) and $\mathrm{A}_{\text {glucosidic }}$ is the integrated signal of glucosidic protons between 3.2 and 4.2 ppm (6 protons for each not protected unit).

The substitution degree SD, corresponding to the number of hydroxyl groups substituted for repetitive unit of dextran was calculated from:

$S D=\frac{3 \times \text { protection }(\%)}{100}$

Table 1, summarizes the obtained results.

Table 1. Protection percent, substitution degree and $\varepsilon$-caprolactone content of the grafted dextrans samples

\begin{tabular}{lcccc}
\hline & g-dextran1 & g-dextran2 & g-dextran3 & g-dextran4 \\
\hline $\begin{array}{l}\text { Percent of } \\
\text { protection }\end{array}$ & $73.9 \%$ & $74.0 \%$ & $87.8 \%$ & $69.0 \%$ \\
$\begin{array}{l}\text { substitution } \\
\text { degree }\end{array}$ & 2.2 & 2.2 & 2.6 & 2.1 \\
$\mathrm{~F}_{\mathrm{PCL}}$ & 0.86 & 0.97 & 0.81 & 0.97 \\
$\mathrm{~F}_{\mathrm{PCL}}$ & 0.77 & 0.92 & 0.78 & 0.82 \\
$*$ from gravimetry. & & &
\end{tabular}

\section{Amount of grafted $\varepsilon$-caprolactone}

The mass ratio of $\varepsilon$-caprolactone grafted over dextran samples was calculated according to:

$$
F_{P C L}=\frac{I_{P C L} \times M_{\varepsilon C L}}{\left\{\left(I_{P C L} \times M_{\varepsilon C L}\right)+\left(\frac{I_{D e x t}}{3}\left[M_{D G}+\left(S D \times M_{S_{i M e}}\right)+\left[(3-S D) \times M_{H}\right]\right]\right)\right\}}
$$

where; $\mathrm{I}_{\mathrm{PCL}}$ is the integrated value of the signals of $\varepsilon-\mathrm{CL}$ calculated from the average value of methylene groups at 4.1 and $2.35 \mathrm{ppm}$; $\mathrm{I}_{\text {Dext }}$ is the integrated value of the signals of methyl and methylene protons of dextran between 3.0 and $4.0 \mathrm{ppm}$; SD is the substitution degree; $\mathrm{M}_{\varepsilon \mathrm{CL}}, \mathrm{M}_{\mathrm{SiMe} 3}, \mathrm{M}_{\mathrm{H}}$ and $\mathrm{M}_{\mathrm{DG}}$ are the molecular weight of $\varepsilon$-caprolactone repeat unit, $\mathrm{SiMe}_{3}$ group, hydrogen and deprotoned glucosidic unit respectively.

The obtained values of $\mathrm{SD}$ and $\mathrm{F}_{\mathrm{PCL}}$ following the previous procedure are also summarized in Table 1 together 
with those obtained by gravimetry after precipitation of the reaction product with heptane.

The values of the fraction in weight of $\varepsilon$-caprolactone obtained from ${ }^{1} \mathrm{H}$ MNR spectra are higher than the corresponding ones calculated by gravimetry. However, even though this last method is reported in the literature, ${ }^{15}$ in our opinion, it is less reliable due to the losses of weight that can be generated in the purification processes of the respective products.

The $\mathrm{F}_{\mathrm{PCL}}$ values are indicative of a considerable amount of $\varepsilon$-caprolactone incorporation on dextran in all cases, and the content of $\varepsilon$-caprolactone increases with the copolymerization time of this over precursor dextrans.

\section{Elemental analysis}

The compositions of the samples obtained by elemental analysis are summarized in Table 2. As expected, the results obtained for the precursory dextrans are very similar to each other. The modified dextrans also show a very similar relationship between the percentage of carbon and hydrogen. Both the content of carbon and hydrogen increases by $\varepsilon$-caprolactone incorporation. This fact is understandable considering that $\varepsilon$-caprolactone has a composition of carbon and hydrogen in mass percentage of $63.1 \%$ and $8.8 \%$ respectively, higher values than those of dextran.

Solubility assays for modified and unmodified dextrans and PCL in several solvents at $298 \mathrm{~K}$ were made. The
Table 2. Elemental analysis results

\begin{tabular}{|c|c|c|c|c|}
\hline Sample & Carbon \% & Hydrogen $\%$ & Carbon $\%^{\mathrm{a}}$ & Hydrogen $\%{ }^{a}$ \\
\hline $\begin{array}{l}\text { Dextran } \\
40,000\end{array}$ & 39.9 & 7.6 & 44.4 & 6.2 \\
\hline $\begin{array}{l}\text { Dextran } \\
10,000\end{array}$ & 39.9 & 7.7 & 44.4 & 6.2 \\
\hline$\varepsilon$-caprolactone & 64.0 & 9.7 & 63.1 & 8.8 \\
\hline g-dextran1 & 57.9 & 10.7 & - & - \\
\hline g-dextran2 & 61.2 & 10.9 & - & - \\
\hline g-dextran 3 & 59.9 & 10.7 & - & - \\
\hline g-dextran4 & 59.7 & 10.8 & - & - \\
\hline
\end{tabular}

${ }^{a}$ calculated according to the respective structures.

obtained results are shown in Table 3. As a comparison parameter among the solvents, their value of Hildebrand parameters, ${ }^{16} \delta$, were used. In Table 3 the solvents are ordered according their $\delta$ value. For modified dextrans, the interval of Hildebrand parameters of solubility for the solvents in those which the samples were solubilized, was 8.2 to 10.0 ; the precursor dextrans are insoluble in this interval. In general the solubility of modified dextrans is increased with respect to precursor dextrans, but it is restricted to solvents less polar than water and methanol. It is important to highlight the insolubility of the modified dextrans in water, although the precursors dextrans are water soluble, since this allows the obtaining of spread monolayers of the modified dextrans at the air-water interface as is detailed later.

Table 3. Solubility of precursors and grafted dextrans

\begin{tabular}{|c|c|c|c|c|c|c|}
\hline Solvent & $\delta\left(\mathrm{cal} \mathrm{cm}^{-3}\right)^{1 / 2}$ & Precursor dextrans & g-dextran 1 & g-dextran2 & g-dextran3 & g-dextran4 \\
\hline Petroleum benzin & 7.3 & I & I & I & I & I \\
\hline Diethylether & 7.4 & I & I & I & I & I \\
\hline Cyclohexane & 8.2 & I & S & S & S & S \\
\hline Carbon tetrachloride & 8.6 & I & S & S & S & S \\
\hline Toluene & 8.9 & I & S & S & S & S \\
\hline Chloroform & 9.3 & I & S & S & S & S \\
\hline Tetrahydrofuran & 9.5 & I & S & S & S & S \\
\hline Cyclohexanone & 9.9 & I & S & S & S & S \\
\hline Dioxane & 9.9 & I & S & S & S & S \\
\hline Acetone & 10 & I & S & S & S & S \\
\hline 1-Butanol & 11.4 & I & I & I & I & I \\
\hline 2-Propanol & 11.5 & I & I & I & I & I \\
\hline Dimethylformamide & 12.1 & I & I & I & I & I \\
\hline Dimethylsulfoxide & 12.9 & $S$ & S & S & $\mathrm{S}$ & $\mathrm{S}$ \\
\hline Methanol & 14.5 & I & I & I & I & I \\
\hline Water & 23.4 & S & I & I & I & I \\
\hline
\end{tabular}

$(\mathrm{I})=$ Insoluble; $(\mathrm{S})=$ Soluble. 
Grafted-dextrans copolymers were also characterized by thermal analysis, thermogravimetric analysis (TGA) were performed. In Figure 2 the thermal degradation profile and the respective first derivative (inserts), obtained by TGA for dextran, PCL and g-dextran1 are shown. Similar profiles of thermal degradation were obtained for the rest of the modified dextrans. From the degradation profiles, the

a)

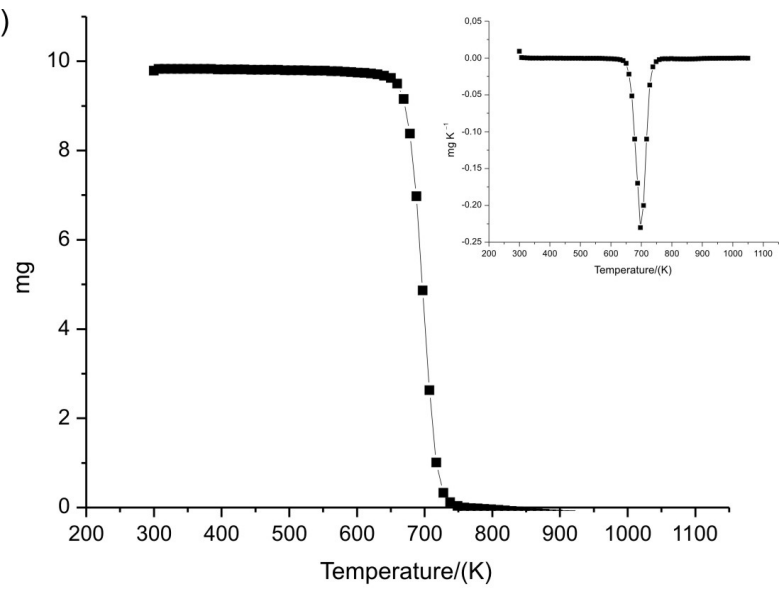

b)

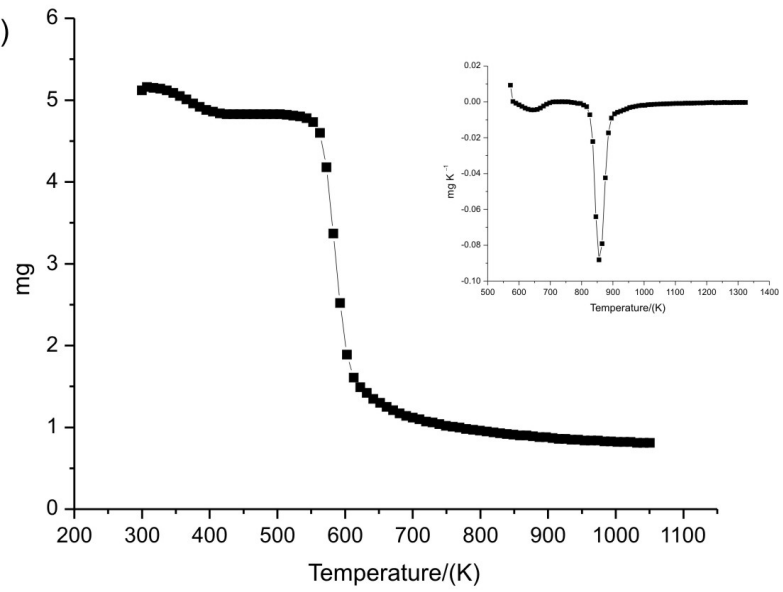

c)

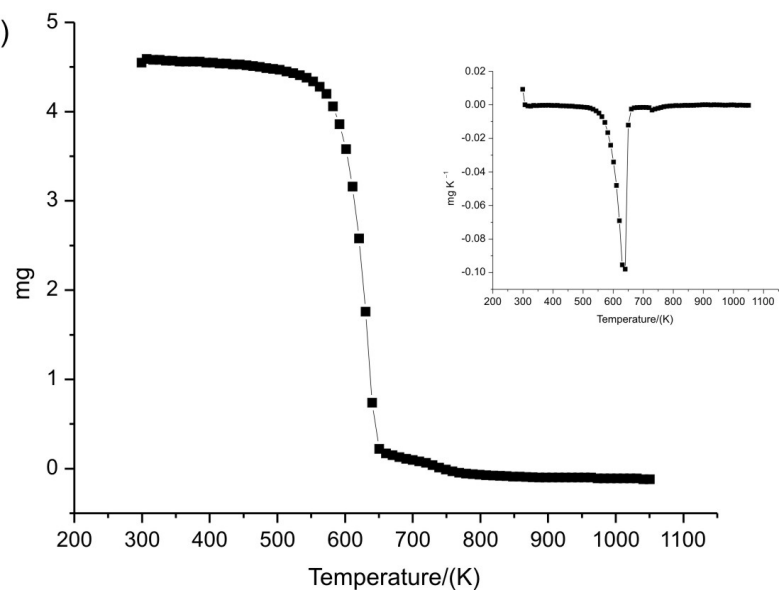

Figure 2. Thermal degradation profiles and the respective first derived obtained by TGA for: PCL (a), unmodified dextran 10,000 $\mathrm{g} \mathrm{mol}^{-1}$ (b), and g-dextran $1(\mathrm{c})$.
Table 4. Temperature of 50\% weight loss $\left(\mathrm{T}_{\mathrm{D}, 50 \%}\right)$, and inflection points obtained from the thermal degradation profiles

\begin{tabular}{lcc}
\hline Sample & $\mathrm{T}_{\mathrm{D}, 50 \%}(\mathrm{~K})$ & Inflection point $(\mathrm{K})$ \\
\hline Dextran 40,000 & 608 & 605 \\
Dextran 10,000 & 598 & 593 \\
g-dextran1 & 635 & 650 \\
g-dextran2 & 653 & 663 \\
g-dextran3 & 660 & 673 \\
g-dextran4 & 638 & 648 \\
PCL & 693 & 708 \\
\hline
\end{tabular}

thermal stability presented as temperature of $50 \%$ weight loss under nitrogen atmosphere, $\mathrm{T}_{\mathrm{D}, 50},{ }^{17-19}$ were obtained. Table 4 summarizes the $T_{D, 50}$ obtained values and the inflection point, IP, obtained from the derived curve. The degradation profiles of all copolymers show very similar patterns, with the main weight loss taking place between 300-450 K. $\mathrm{T}_{\mathrm{D}, 50}$ values indicate that PCL is thermally more stable than dextran and the copolymers present an intermediate stability to both homopolymers. The analysis of this data allows concluding that the incorporation of $\varepsilon$-caprolactone causes the modified dextran to present a higher thermal stability than the respective precursory dextrans.

\section{Surface energy of thin films}

Surface energy SE for thin superficial films of samples spin-coated over glass slides was determined using wettability measurements. The contact angles of water and $\mathrm{CH}_{2} \mathrm{I}_{2}$ over these films were determined, the surface energy $\mathrm{g}$ for the four dextran samples, and the dispersion and polar components $\gamma^{\mathrm{d}}$ and $\gamma^{\mathrm{p}}$ were calculated by the method of Owens and Wendt ${ }^{13}$ and Kaelble. ${ }^{14}$ The results are summarized in Table 5. A decrease in $\gamma$ is obtained when the $\varepsilon$-caprolactone content increases. The same behavior in the polar contribution $\gamma^{\mathrm{p}}$ is obtained, at equality of molecular weight of the precursory dextran. In both 10,000 and $40,000 \mathrm{~g} \mathrm{~mol}^{-1}$, a decrease is obtained in the polar contribution to the surface energy when the $\varepsilon$-caprolactone content increases. This result is consistent with the hydrophobicity of $\varepsilon$-caprolactone; it is important to remember that due to this hydrophobic character, $\varepsilon$-caprolactone blocks form a hydrophobic core in aqueous block copolymer micelles. ${ }^{20,21}$

\section{Monolayers at the air-water interface}

Monolayers at the air-water interface were obtained and studied by compression using the Langmuir technique. The spreading solvent used in all cases was chloroform. The Langmuir isotherms obtained are shown in Figure 3 for all $\varepsilon$-caprolactone-grafted dextrans. Two 
Table 5. Contact angles, surface energy SE, dispersion and polar contribution

\begin{tabular}{|c|c|c|c|c|c|c|}
\hline \multirow{2}{*}{ Sample } & \multicolumn{2}{|c|}{ Contact angle } & \multirow{2}{*}{$\begin{array}{l}\text { Surface energy } \\
\quad\left(\mathrm{mN} \mathrm{m}^{-1}\right)\end{array}$} & \multirow{2}{*}{$\begin{array}{l}\text { Dispersion contribution } \\
\qquad \gamma^{\mathrm{d}}\left(\mathrm{mN} \mathrm{m}^{-1}\right)\end{array}$} & \multirow{2}{*}{$\begin{array}{l}\text { Polar contribution } \\
\quad \gamma^{\mathrm{P}}\left(\mathrm{mN} \mathrm{m}^{-1}\right) \\
\end{array}$} & \multirow{2}{*}{$\begin{array}{l}\% \text { of Polar } \\
\text { contribution }\end{array}$} \\
\hline & $\theta_{\text {water }}$ & $\theta_{\mathrm{CH} 212}$ & & & & \\
\hline g-dextran 1 & 65.3 & 75.4 & 44.3 & 31.2 & 13.2 & 29.8 \\
\hline g-dextran2 & 81.2 & 47.9 & 35.9 & 30.4 & 5.5 & 15.3 \\
\hline g-dextran 3 & 70.9 & 41.6 & 41.2 & 31.6 & 9.6 & 23.3 \\
\hline g-dextran4 & 80.1 & 54.2 & 33.8 & 26.7 & 7.1 & 21.0 \\
\hline
\end{tabular}

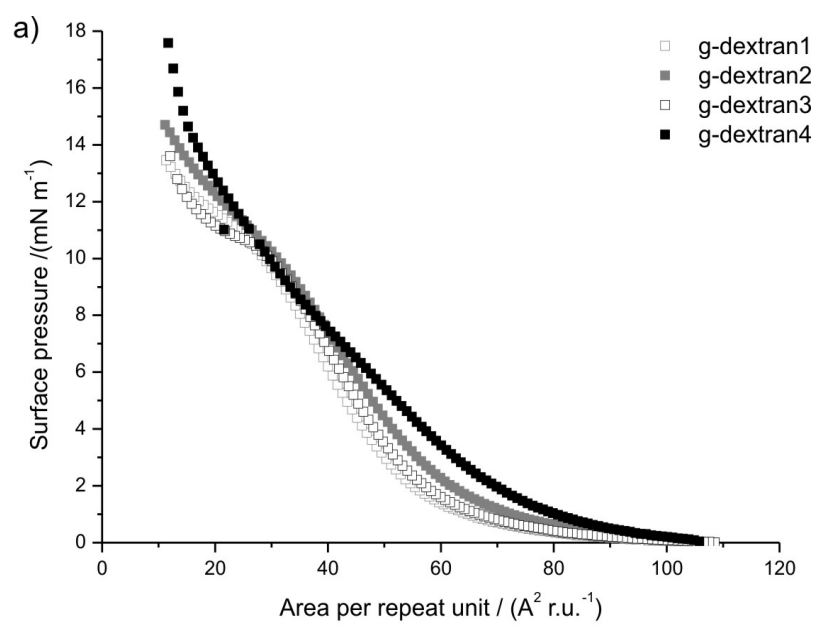

b)

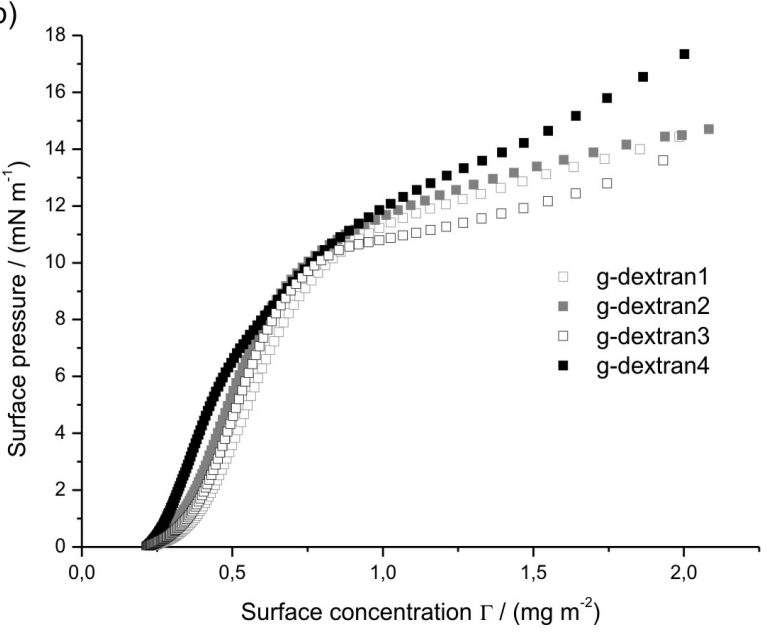

Figure 3. Surface pressure-area isotherms for $\varepsilon$-caprolactone grafteddextrans; surface pressure $v s$. area per repeat unit (a) and surface pressure $v s$. surface concentration (b).

representations of the isotherms are shown: the surface pressure in function of the surface area and in function of the surface concentration.

The obtained isotherms are of the expanded type, ${ }^{22,23}$ i.e., surface pressure increases gradually by monolayer compression. The initial increase of the surface pressure appears at lower area per repeat unit for g-dextran 1 monolayer than for g-dextran 2 monolayer and the same behavior is presented by g-dextran 3 compared with g-dextran4, Figure 3a, therefore this transition happens at lower area per repeat unit when lower is the content of $\varepsilon$-caprolactone in the sample. Our group has reported a schematic model of the $\varepsilon$-caprolactone/polyethylene oxide copolymer behavior at the air-water interface, ${ }^{24}$ inspired by Duran and coworkers. ${ }^{25}$ In this model we propose that the hydrophilic blocks form loops toward the water subphase while $\varepsilon$-caprolactone blocks remain spread at the interface. This model can also be assumed here, thus explaining the results previously mentioned. In the $\varepsilon$-caprolactone grafteddextrans, dextran portions in the samples could form loops when being guided toward the water subphase, explaining the fact that the initial surface pressure increase appears at lower area per repeat unit for monolayers of the samples with higher dextran content or lower content of $\varepsilon$-caprolactone. Another important observation is the fact that, between approximately 1 to $10 \mathrm{mN} \mathrm{m}^{-1}$ of surface pressure, at the same surface concentration, $\pi$ is higher for the samples with a higher $\varepsilon$-caprolactone content. This result is consistent with the previous explanation, since $\varepsilon$-caprolactone blocks remain spread at the interface, increasing $\pi$.

Compression-expansion studies were performed for all samples of grafted dextran, the expansion was performed immediately after that the compression was completed until $11 \mathrm{mN} \mathrm{m}^{-1}$ of surface pressure. The compression-expansion cycles do not show hysteresis for all samples. Figure 4 show

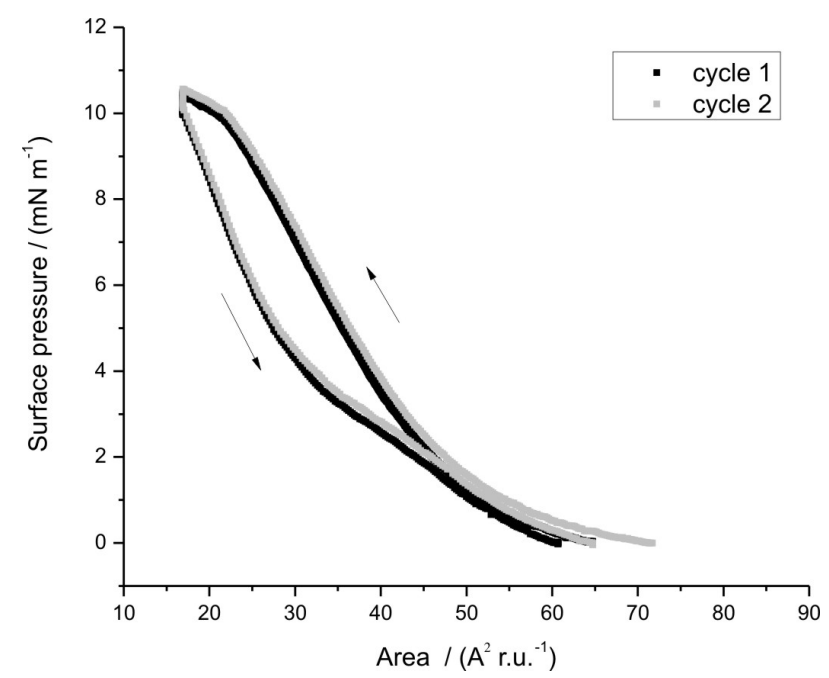

Figure 4. Compression- expansion cycles for g-dextran3 monolayer at $16.7 \mathrm{~mm}^{2} \mathrm{~s}^{-1}$ barrier speed. 

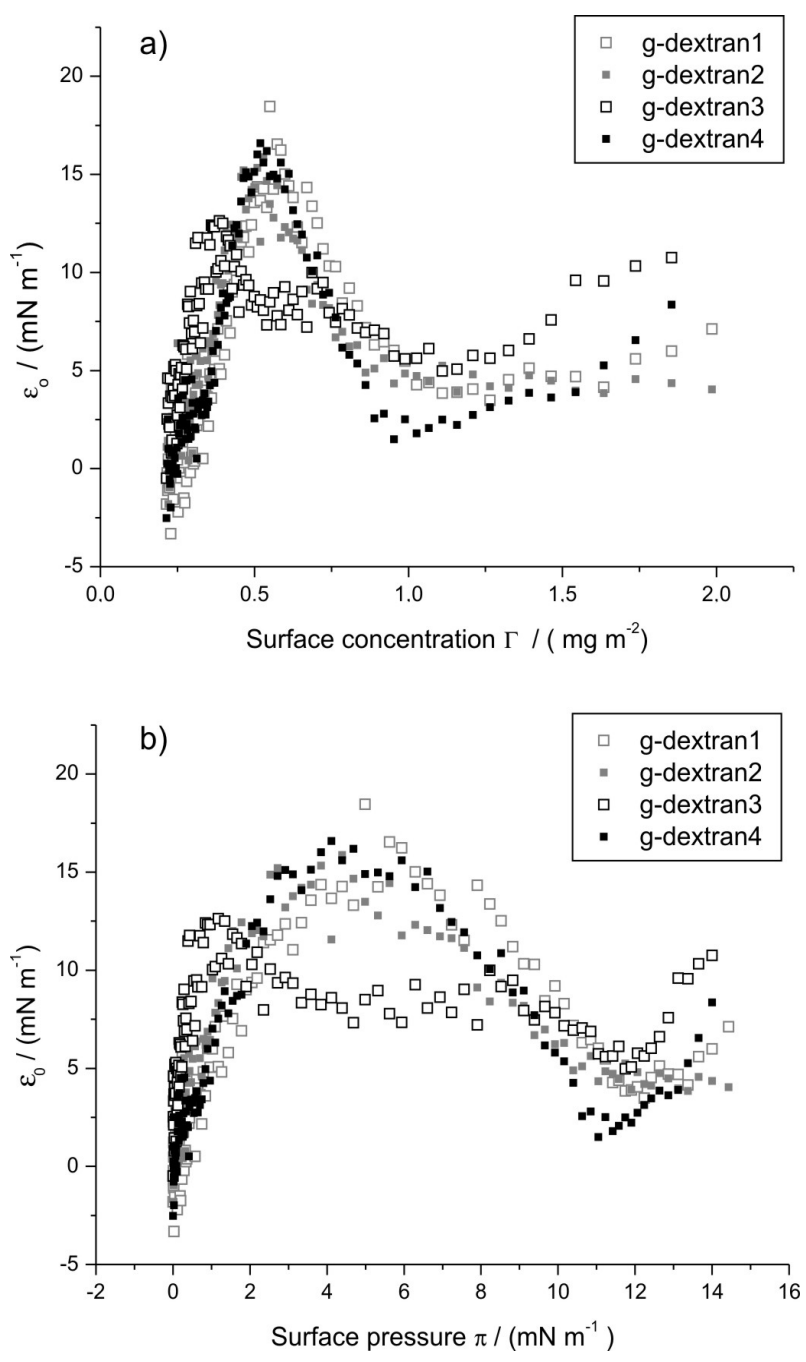

Figure 5. Static surface elasticity $\varepsilon_{0}$ of monolayers, in function of surface concentration (a) and surface pressure (b).

the behavior of g-dextran3 as an example; the monolayer material does not retain their configuration during its expansion after a compression, this indicate that the chains not have enough time to recover the initial conformation in the expansion process; however with a later compression the obtained isotherm is practically the same. When the compression reaches surface pressure values higher than $13 \mathrm{mN} \mathrm{m}^{-1}$, for all grafted dextran samples was impossible to obtain the isotherm again, this would be indicative of an irreversible collapse of the monolayers around this value of surface pressure.

Tests of monolayers stability were also performed, the surface pressure variation in function of the time was measured at $8 \mathrm{mN} \mathrm{m}^{-1}$, only a slight decrease after an average of $60 \mathrm{~min}$ was obtained for all samples. These results indicate a high stability of the monolayers.

The static surface elasticity for the monolayers, $\varepsilon_{\mathrm{o}}$, a parameter that indicates the effect of an area change on the surface pressure, was obtained from the isotherm surface pressure $v s$. surface area $(\pi v$. A) by,

$\varepsilon_{o}=-A\left(\frac{\partial \pi}{\partial A}\right)_{T}$

In Figure 5 the static surface elasticity of the monolayers of g-dextran1, g-dextran2, g-dextran3, and g-dextran 4 are shown. Two representations, $\varepsilon_{\mathrm{o}} v s . \pi$ and $\varepsilon_{\mathrm{o}} v s . \Gamma$ are shown. The maximum static surface elasticity, where an area change produces a larger effect on the surface pressure, is around $4-5 \mathrm{mN} \mathrm{m}^{-1}$ of surface pressure. After this, a minimum of $\varepsilon_{\mathrm{o}}$ is obtained between 10 and $12 \mathrm{mN} \mathrm{m}^{-1}$ for all samples, and finally at higher pressures the monolayers collapse. In the surface concentration scale, the maximum static surface elasticity for copolymers is obtained between 0.30 and $0.60 \mathrm{mg} \mathrm{m}^{-2}$. According to these results, the static surface elasticity $\varepsilon_{0}$ shows higher values and the surface pressure is more sensitive to changes in area or surface concentration in the semidilute region. This behavior seems to be general for polymeric systems. ${ }^{26,27}$

\section{Conclusions}

A series of biodegradable graft copolymers were synthesized by grafting $\varepsilon$-caprolactone over the polysaccharide dextran of different molecular weight. The obtained products showed the capacity to form stable monolayers at the air-water interface, and the properties of these monolayers were dependent on the $\varepsilon$-caprolactone content. In addition, the surface energy of copolymer spin coated thin films was also dependent on the composition. Therefore we can conclude that: the surface properties of grafted copolymers can be modulated by composition control. Consequently, $\varepsilon$-caprolactone grafted- dextrans have the potential for being used in different fields such as coating, stabilization of dispersions and nanocapsule synthesis, among others applications, where the surface properties are relevant.

\section{Acknowledgment}

The authors acknowledge Fondecyt grants, Chile (1080238 and 1040550) for the partial financial support for this work.

\section{References}

1. Shalaby, S. W. and Burg, K. J. L.; Absorbable and Biodegradable Polymers, CRC press: New York, 2004. 
2. Rusa, C.; Toneli, A.; Macromolecules 2000, 33, 5321.

3. Leiva, A.; Gargallo, L.; González, A.; Araneda, E.; Radic' D.; Eur. Polym. J. 2006, 42, 316.

4. Bajgai, M.; Aryal, S.; Lee, D.; Park, S.; Kim, H.; Colloid Polym. Sci. 2008, 286, 517.

5. Gref, R.; Rodrigues, J.; Couvreur, P.; Macromolecules 2002, 35, 9861.

6. Shi, R.; Burt, H.; Int. J. Pharm. 2004, 271, 167.

7. Nouvel, C.; Frochot, C.; Sadtler, V.; Dubois, P.; Dellacherie, E.; Six, J-L.; Macromolecules 2004, 37, 4981.

8. Raynaud, J.; Choquenet, B.; Marie, E.; Dellacherie, E.; Nouvel, C.; Six, J-L.; Durand, A.; Biomacromolecules 2008, 9, 1014.

9. Bosker, W. T. E.; Agoston, K.; Cohen Stuart, M. A.; Norde, W.; Timmermans, J. W.; Slaghek, T. M.; Macromolecules 2003, 36, 1982.

10. Rouzes, C.; Durand, A.; Leonard, M.; Dellacherie, E.; J. Colloid Interface Sci. 2002, 253, 217.

11. Ydens, I.; Rutot, D.; Degée, P.; Six, J-L.; Dellacherie, E.; Dubois, P.; Macromolecules 2000, 33, 6713.

12. Nouve1, C.; Dubois, P.; Dellacherie, E.; Six, J-L.; Biomacromolecules 2003, 4, 1443.

13. Owens, D. K.; Wendt, R. C.; J. Appl. Polym. Sci. 1969, 13, 1741.

14. Kaelble, D. H.; J. Adhes. 1970, 2, 66.

15. Nouvel, C.; Ydens, I.; Degée, P.; Dubois, P.; Dellacherie, E.; Six, J-L.; Polymer 2002, 43,1735.

16. Hildebrand, J. H.; Scott, R. L.; The Solubility of Non Electrolytes, $3^{\text {rd }}$ ed., Dover Publication Inc. : New York, 1964.
17. Li, X.; Hay, A. S.; Macromolecules 2006, 39, 3714.

18. Wu, C. W.; Tsai, C. M.; Lin, H. C.; Macromolecules 2006, 39 , 4298.

19. Li, J.; Ni, X.; Zhou, Z.; Leong, K. W.; J. Am. Chem. Soc. 2003, $125,1788$.

20. Leiva, A.; Quina, F. H.; Araneda, E.; Gargallo, L.; Radic', D.; J. Colloid Interface Sci. 2007, 310, 136.

21. Lim Soo, P.; Luo, L.; Maysinger, D.; Eisenberg, A.; Langmuir 2002, 18, 9996.

22. Gaines, G.; Insoluble Monolayers at Liquid-Gas Interfaces, Interscience: New York, 1966.

23. Crisp, D. J. In Surface Phenomena in Chemistry and Biology; Danielli, J. F.; Pankhurst, K. G. A.; Riddiford A. C.; eds., Pergamon, Elmsford: New York, 1958.

24. Leiva, A.; Farias, A.; Gargallo, L.; Radic', D.; Eur. Polym. J. 2008, 44, 2589.

25. Joncheray, T. J.; Denoncourt, K. M.; Meier, M. A. R.; Schubert, U. S.; Duran, R. S.; Langmuir 2007, 23, 2423.

26. Monroy, F.; Ortega, F.; Rubio, R. G..; Phys. Rev. E: Stat., Nonlinear, Soft Matter Phys. 1998, 58, 7629.

27. Ferenczi, T. A. M.; Cicuta, P.; J. Phys.: Condens. Matter 2005, $17, \mathrm{~s} 3345$.

Received: March 10, 2009

Web Release Date: October 16, 2009 